\title{
Translation, cross-cultural adaptation, and validation of the Canadian Diabetes Risk Questionnaire for the Brazilian population
}

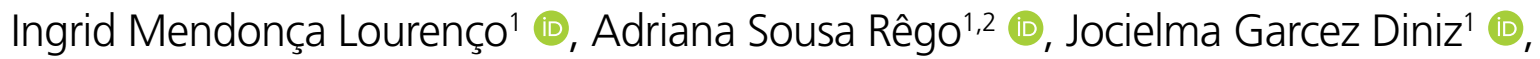 \\ Maryângela Godinho Pereira Bena ${ }^{3}$ (D) Weslley da Silva Barbosa Moreira ${ }^{4}$ (D), \\ Patrícia Rodrigues Ferreira' ${ }^{1}$ (D) Karla Virgínia Bezerra de Castro Soares ${ }^{1,5}$ (D), \\ Lucivalda Viegas de Almeida² (ㅁ), Rudys Rodolfo de Jesus Tavarez ${ }^{5}$ (D), Daniela Bassi-Dibai ${ }^{1,25 *}$
}

\section{SUMMARY}

OBJECTIVE: The aim of this study was to translate, cross-culturally adapt, and validate the Canadian Diabetes Risk Questionnaire for use in Brazilian Portuguese.

METHODS: This is a Questionnaire validity study conducted at a private university. The Brazilian version of the Canadian Diabetes Risk Questionnaire was developed by means of the processes of translation, back-translation, committee review, and pretesting. Test-retest reliability was measured using the intraclass correlation coefficient and kappa coefficient. Internal consistency was measured using Cronbach's alpha. For construct validity, the total score of the Canadian Diabetes Risk Questionnaire was correlated with the Diabetes Knowledge Scale and the Diabetes Mellitus Risk Questionnaire. Ceiling and floor effects were also evaluated in the present study.

RESULTS: For construct validity and floor and ceiling effect measurements, a total sample of 100 participants was used. For reliability, a subsample of 34 participants out of the total sample was used. We identified adequate values for reliability (kappa between $0.46-1.00$ and ICC 0.96) and internal consistency (Cronbach's alpha 0.80). There were significant correlations between the Canadian Diabetes Risk Questionnaire and the Diabetes Mellitus Risk Questionnaire $\left(r_{s}=0.370, p<0.001\right)$, but not the Diabetes Knowledge Scale $\left(r_{s}=-0.162\right)$. No ceiling or floor effects were found.

CONCLUSION: We concluded that in accordance with the best international recommendations, the Brazilian version of the Canadian Diabetes Risk Questionnaire has adequate psychometric properties.

KEYWORDS: Diabetes mellitus. Questionnaire. Primary health care.

\footnotetext{
'Universidade Ceuma, Department of Physical Therapy - São Luís (MA), Brazil.

${ }^{2}$ Universidade Ceuma, Postgraduate Program in Programs Management and Health Services - São Luís (MA), Brazil.

${ }^{3}$ Universidade Ceuma, Medical Clinic, Nursing - São Luís (MA), Brazil.

${ }^{4}$ Centro de Estudos Superiores de Maceió, Department of Nursing - Maceió (AL), Brazil.

${ }^{5}$ Centro de Estudos Superiores de Maceió, Postgraduate Program in Dentistry - São Luís (MA), Brazil.

*Corresponding author: danielabassifisio@gmail.com

Conflicts of interest: the authors declare there is no conflicts of interest. Funding: This work was financially supported by Coordenação de Aperfeiçoamento de Pessoal de Nível Superior (CAPES - finance code 001).

Received on August 02, 2021. Accepted on August 19, 2021.
} 


\section{INTRODUCTION}

The number of individuals with diabetes mellitus (DM), especially type 2 (DM2), has been increasing in recent years, and it is considered a public health problem in several parts of the world ${ }^{1}$. The identification of individuals at high risk of developing prediabetes and DM2 is important, since it allows interventions focused on reducing the risk of mortality and complications secondary to the disease, which are divided into macrovascular (heart disease, stroke ${ }^{2}$, and decreased heart rate variability $^{3}$, which implies a worse prognosis) and microvascular (retinopathy, nephropathy, and neuropathy $)^{4}$. Additionally, identifying individuals at high risk of developing DM can promote early glycemic control, which is crucial to prevent the aforementioned complications ${ }^{2}$.

In this context, the use of simple implementation and with adequate cost-effectiveness has been encouraged, especially in primary care, to prevent the onset of DM2. Faced with this scenario, the use of questionnaires has been widely explored in the screening of various diseases ${ }^{5-9}$.

The Canadian Diabetes Risk Questionnaire (CANRISK), originally created and validated in Canada, was developed by the Public Health Agency of Canada with the aim of identifying the risk of prediabetes or DM2 ${ }^{10}$. In Brazil, there is a questionnaire with the objective of also tracking the risk of developing DM2, called the FINDRISC ${ }^{11}$. However, the CANRISK presents more items that may be related to the risk of developing DM2, such as ethnicity and educational level. In complement, the CANRISK has already been cross-culturally adapted and validated for the Chinese population ${ }^{12}$. Thus, considering the importance of instruments that track the risk of developing DM2, especially in the field of primary care, the objective of this study was to translate, cross-culturally adapt, and validate the CANRISK for use in Brazilian Portuguese.

\section{METHODS}

\section{Study design}

This is a translation, cross-cultural adaptation, and validity study conducted according to the Guidelines for the Process of Cross-cultural Adaptation of Self-Report Measures ${ }^{13}$ and the COnsensus-based Standards for the selection of health Measurement INstruments (COSMIN) ${ }^{14}$. Authorization for translation, cross-cultural adaptation, and validation of the CANRISK in Brazilian Portuguese was granted via email by the author of the original version of the questionnaire (Dr. Janusz Kaczorowski).

This research was approved by the institution's Human Research Ethics Committee under opinion number 2.853.570.
All participants validated their participation by signing an informed consent form. The recruitment of individuals took place in the university community, in the communities surrounding the university, and in a community association in the city of São Luís (MA, Brazil). The research was disseminated through pamphlets and social media.

\section{Translation and cross-cultural adaptation of the Canadian Diabetes Risk Questionnaire}

The process of translating and cross-cultural adaptation of the CANRISK into Brazilian Portuguese followed the criteria of Beaton et al. ${ }^{13}$ and was carried out in five phases, as described below:

(1) Translation: two independent translators, both with Brazilian Portuguese as the mother tongue and fluent in English, performed the translation of the original version of the questionnaires into Brazilian Portuguese.

(2) Synthesis of the translations: after discussions and reviews, the two translators, under observation of one of the researchers, synthesized the two versions of the questionnaires translated independently and produced a single version in a consensual way.

(3) Back-translation: two independent translators (without technical knowledge of health issues), both with English as the mother tongue and fluent in Portuguese, performed the translation of the Portuguese version of the questionnaires back into English, without prior knowledge of the original version of the questionnaire.

(4) Analysis of a committee of experts: six diabetes specialists together with the four translators of this study analyzed the original version and the translated, synthesized, and back-translated versions and defined the pre-final version of the CANRISK, which we now call the CANRISK.

(5) Test of the pre-final version: the pre-final version of the questionnaire was applied to 30 individuals without a diagnosis of diabetes and with the Portuguese language as their mother tongue, assessing the understanding of the items and responses of the CANRISK by these respondents.

\section{Participants}

To calculate the sample size for this validation study, COSMIN was used, with a minimum number of 100 individuals recommended $^{14}$. As eligibility criteria, we considered individuals of both sexes, without the diagnosis of type 1 or type $2 \mathrm{DM}$, 
aged between 40-74 years, and without cognitive deficits or any other limitations that prevented them from answering the questionnaire.

\section{Canadian Diabetes Risk Questionnaire}

The CANRISK is a questionnaire containing 12 items that assess the risk of prediabetes or DM2. It is mainly used for adults aged 45-74 years. The final CANRISK score ranges from $0-87$ points and can be categorized as follows: score $<21$ points, the individual is at low risk; between $21-32$ points, the individual is at moderate risk; and $>33$ points, an individual is at high risk for developing DM2.

\section{Other questionnaires}

In addition to the CANRISK, two other questionnaires already adapted and validated for Brazilian Portuguese were applied to carry out construct validity:

(1) Diabetes Knowledge Scale (DKN-A), a questionnaire validated for the Brazilian population by Torres et al. ${ }^{8}$, composed of 15 multiple-choice questions on various aspects related to the general knowledge of DM2. The total score was calculated by assigning 1 point for each correct answer, ranging from $0-15$. The higher the score, the greater the knowledge about DM2.

(2) Diabetes Mellitus Risk Questionnaire (DMRQ), a questionnaire validated in the master's dissertation by Cruz et al. ${ }^{15}$, composed of seven items and with a total score ranging from 0 to 27 points. The higher the score, the higher the risk of developing DM2.

\section{Statistical analysis}

Descriptive analysis was initially performed with the presentation of quantitative data using means and standard deviations and qualitative data using absolute numbers and percentages. Comparisons between the total sample and the subsample were performed using the paired $t$ test or $\chi^{2}$ test.

Test-retest reliability was assessed using the kappa coefficient, intraclass correlation coefficient (ICC), standard error of measurement (SEM), and minimum detectable change (MDC). Internal consistency was assessed using Cronbach's alpha.

The kappa values were interpreted as follows: $<0$, poor; $0.01-0.20$, slight; $0.21-0.40$, fair; $0.41-0.60$, moderate; $0.61-0.80$, substantial; and $0.81-1$, almost perfect ${ }^{16}$. The ICC values were interpreted as follows: for values $<0.40$, reliability was considered low; between $0.40-0.75$, moderate; between 0.75-0.90, substantial; and $>0.90$, excellent ${ }^{17}$. The SEM percentage was interpreted as follows: $\leq 5 \%$, very good; $>5 \%$ and $\leq 10 \%$, good; $>10 \%$ and $\leq 20 \%$, doubtful; and $>20 \%$, negative ${ }^{18}$.
Kolmogorov-Smirnov normality test was applied; however, due to the non-normal distribution of data, Spearman's correlation coefficient $\left(r_{s}\right)$ was used to determine the magnitude of the correlations between the CANRISK, the DMRQ, and the DKN-A. The magnitude of the correlations was interpreted in accordance with the COSMIN recommendations: correlations with instruments measuring similar constructs should be $\geq 0.50$; correlations with instruments measuring related but dissimilar constructs should be $0.30-0.50$; and correlations with instruments measuring unrelated constructs should be $<0.30^{14}$.

Ceiling and floor effects were also evaluated in the present study. By definition, these effects occurred when a number of study participants (set as over 15\%) reached the minimum or maximum values of the total score of the questionnaire.

All statistical analyses were performed using SPSS software, version 17.0 (Chicago, IL, USA), and a significance level of $5 \%$ was adopted.

\section{RESULTS}

With regard to translation and cross-cultural adaptation, to facilitate understanding of the questionnaire, the committee of experts suggested the following changes: use the name of the country instead of nationality in the item that addresses the ethnicity of biological parents (item 11) (e.g., change "Chinese" to "China") and inclusion of the country Japan in East Asia in this same item. This adapted version of the CANRISK was then applied to 30 participants to assess the level of understanding of the items. There was $100 \%$ understanding of all items in the questionnaire. Thus, we defined the final Brazilian Portuguese version of the CANRISK.

A total of 100 participants was recruited and included in the study. Out of this total sample, a subsample of 34 participants was selected for the test-retest reliability calculations. Table 1 presents the characteristics of the sample, and we observed that most of the participants were women, married, and overweight.

Regarding the reliability (Tables 2 and 3), when considering each item of the CANRISK, we observed adequate values of reliability (kappa $\geq 0.46$ ). Item 6 was the least reliable (kappa $=0.46$ ), and items $1,2,3,4,5$, and 7 were the most reliable (kappa $=1.00$ ). Considering the total score, we observed adequate reliability $(\mathrm{ICC}=0.96)$ and internal consistency (Cronbach's alpha $=0.80$ )

To assess the construct validity by means of correlation with a validated questionnaire (Table 4), we observed adequate correlations of the CANRISK score with the DMRQ $\left(r_{s}=0.370\right)$. No participants achieved a CANRISK maximum score of 100 or 0 . Thus, ceiling and floor effects were not observed. 
Table 1. Sociodemographic and clinical characteristics of the participants.

\begin{tabular}{l|c|c|c} 
& Reliability phase $(\mathrm{n}=34)$ & Validity phase $(\mathrm{n}=100)$ & p-value \\
\hline Age (years) & $54.00(9.50)$ & $53.70(8.04)$ & 0.130 \\
\hline Gender (female), $\mathrm{n}(\%)$ & $27(79.4)$ & $79(79)$ & 0.000 \\
\hline Marital status, $\mathrm{n}(\%)$ & & & \\
\hline Single & $11(32.4)$ & $32(32)$ & \\
\hline Married & $20(58.8)$ & $55(55)$ & \\
\hline Divorced & $1(2.9)$ & $7(7)$ & 0.696 \\
\hline Widower & $2(5.9)$ & $6(6)$ & 0.999 \\
\hline Weight (kg) & $60.61(19.01)$ & $65.21(16.32)$ & 0.173 \\
\hline Height (m) & $1.57(0.09)$ & $1.57(0.09)$ & \\
\hline BMI (kg/m $)$ & $24.10(7.44)$ & $26.11(6.38)$ & 0.091 \\
\hline Schooling, $\mathrm{n}(\%)$ & & & \\
\hline Basic education & $13(38.2)$ & $46(46)$ & 1.000 \\
\hline High school & $15(44.1)$ & $47(47)$ & 0.787 \\
\hline Higher education & $6(17.6)$ & $7(7)$ & 0.889 \\
\hline Physical activity (yes), $\mathrm{n}(\%)$ & $11(32.4)$ & $33(33)$ & 0.360 \\
\hline Smoker (yes), $\mathrm{n}(\%)$ & $1(2.9)$ & $4(4)$ & 0.081 \\
\hline DKN-A (score) & $7.26(2.76)$ & $7.46(2.59)$ & \\
\hline DMRQ (score) & $11.44(4.22)$ & $11.87(4.15)$ & \\
\hline CANRISK (score) & $28.41(11.36)$ & $31.78(13.05)$ & \\
\hline
\end{tabular}

BMI: body mass index; DKN-A: Diabetes Knowledge Scale; DMRQ: Diabetes Mellitus Risk Questionnaire; CANRISK: Canadian Diabetes Risk Questionnaire. Values are presented in mean (standard deviation) or number (percentage). There was no significant difference between groups ( $p>0.05$, paired $t$ test or $\chi^{2}$ test).

Table 2. Reliability and internal consistency of items of the Canadian Diabetes Risk Questionnaire.

\begin{tabular}{c|c|c|c|c}
\multirow{2}{*}{$\begin{array}{c}\text { CANRISK } \\
\text { item number }\end{array}$} & \multicolumn{2}{|c|}{ Mean (SD) } & \multirow{2}{*}{ Kappa } & $\begin{array}{c}\text { Cronbach's alpha if } \\
\text { item excluded }\end{array}$ \\
\cline { 2 - 3 } 1 & $8.29(5.11)$ & $8.29(5.11)$ & 1.00 & 0.79 \\
\hline 2 & $1.23(2.46)$ & $1.23(2.46)$ & 1.00 & 0.81 \\
\hline 3 & $3.23(3.49)$ & $3.23(3.49)$ & 1.00 & 0.78 \\
\hline 4 & $3.82(2.47)$ & $3.82(2.47)$ & 1.00 & 0.79 \\
\hline 5 & $0.64(0.48)$ & $0.64(0.48)$ & 1.00 & 0.80 \\
\hline 6 & $0.76(0.98)$ & $0.94(1.01)$ & 0.46 & 0.80 \\
\hline 7 & $1.52(1.97)$ & $1.52(1.97)$ & 1.00 & 0.80 \\
\hline 8 & $2.05(5.03)$ & $3.29(6.02)$ & 0.71 & 0.80 \\
\hline 9 & $0.05(0.23)$ & $0.02(0.17)$ & 0.65 & 0.80 \\
\hline 10 & $1.05(1.49)$ & $0.94(1.22)$ & 0.90 & 0.80 \\
\hline 11 & $3.26(2.26)$ & $2.79(1.90)$ & 0.75 & 0.79 \\
\hline 12 & $2.29(2.19)$ & $2.26(2.21)$ & 0.96 & 0.80 \\
\hline
\end{tabular}

CANRISK: Canadian Diabetes Risk Questionnaire; SD: standard deviation. Values are presented as mean (SD).

Table 3. Reliability of the total score of the Canadian Diabetes Risk Questionnaire.

\begin{tabular}{l|c|c|c|c|c|c|c} 
Test & Retest & ICC $(95 \% \mathrm{Cl})$ & $\begin{array}{c}\text { SEM } \\
(\text { absolute })\end{array}$ & $\begin{array}{c}\text { SEM } \\
(\%)\end{array}$ & $\begin{array}{c}\text { MDC } \\
\text { (absolute) }\end{array}$ & $\begin{array}{c}\text { MDC } \\
(\%)\end{array}$ & $\begin{array}{c}\text { Cronbach's } \\
\text { alpha }\end{array}$ \\
\hline $28.41(11.36)$ & $29.02(11.41)$ & $0.96(0.92-0.98)$ & 2.28 & 7.93 & 6.31 & 21.98 & 0.80 \\
\hline
\end{tabular}

ICC: intraclass correlation coefficient; Cl: confidence interval; SEM: standard error of measurement; MDC: minimum detectable change. Data are presented as mean (SD). 
Table 4. Correlation between the total score of the Canadian Diabetes Risk Questionnaire and the other questionnaires applied in the study sample $(n=100)$.

\begin{tabular}{l|c}
\hline Questionnaires & CANRISK \\
\hline DKN-A & $r_{s}=-0.162, p=0.120$ \\
\hline DMRQ & $r_{s}=0.370, p<0.001 *$ \\
\hline
\end{tabular}

DKN-A: diabetes knowledge scale; DMRQ: diabetes mellitus risk questionnaire. *Statistically significant correlation ( $p<0.05$, Spearman's correlation coefficient).

\section{DISCUSSION}

The main findings of this study are that

(i) the CANRISK in the Brazilian Portuguese language has an adequate level of understanding by the population studied and

(ii) the CANRISK presents acceptable values of reliability, internal consistency, and validity, thus confirming the initial hypothesis of the study.

Although the CANRISK is available in 13 other countries (languages: English, French, Chinese, Gujarati, Korean, Persian/Farsi, Punjabi, Spanish, Tagalog, Tamil, Urdu, and Vietnamese) ${ }^{10}$, to the best of our knowledge, these translations do not seem to have cross-cultural adaptation and validation in accordance with best international practices ${ }^{14}$. There are only two versions of the CANRISK adapted cross-culturally and validated, one for Chinese with appropriate psychometric properties (CHINARISK) ${ }^{12}$ and other for the Arabic version (ARABRISK) ${ }^{19}$. It is also worth mentioning that the ARABRISK performed the test-retest on the same day, which is not an advisable practice according to the COSMIN guideline ${ }^{14}$.

Among the psychometric properties that an instrument must have, the COSMIN highlights the

(i) reliability,

(ii) validity (composed of several sub-items, such as face, content, construct, structural, cross-cultural, and criterion validity), and

(iii) responsiveness. Our validation study involved the reliability (using kappa, ICC, SEM, and MDC), cross-cultural validity (using translation, synthesis of translations, back-translation, expert committee, and pre-final version testing), construct validity (using the correlation between questionnaires), and internal structure validity (using Cronbach's alpha) ${ }^{14}$. Thus, such properties already ensure that the CANRISK can be applied to the Brazilian population.

In the Brazilian Portuguese language, the FINDRISC tool is available to tracking the risk of developing DM2 ${ }^{11}$. Comparing the results of the Brazilian version of the FINDRISC versus CANRISK, we observed that both have acceptable measurement properties, with ICC values $>0.90$, kappa values $>0.40$, Cronbach's alpha values $>0.75$, and significant correlations $(\mathrm{p}<0.05)$ with other instruments already validated in the Brazil. However, the FINDRISC has slightly higher values. Thus, health professionals who are interested in tracking the risk of developing DM2 can choose to use the FINDRISC or CANRISK.

This study has limitations that must be expressed, as well as suggestions. Initially, we recommend testing the cross-cultural adaptation of the CANRISK for other languages based on the $\operatorname{COSMIN}^{14}$, a fact that greatly limited the discussion of the results. In addition, due to the need for specific methodology, our study did not investigate the accuracy or responsiveness of the CANRISK. Thus, we suggest that future studies measure these properties. We conducted the present study with a specific sample from a city in northeastern Brazil; therefore, we suggest that future studies be carried out testing this Brazilian version of the CANRISK on larger samples and in different regions of the country.

\section{CONCLUSION}

The Brazilian Portuguese version of the CANRISK has adequate psychometric properties according to the best scientific recommendations.

\section{AUTHORS' CONTRIBUTIONS}

IML: Conceptualization, Data curation, Formal Analysis, Methodology, Writing - original draft. ASR: Conceptualization, Data curation, Formal Analysis, Methodology, Project administration, Writing - review \& editing. JGD: Conceptualization, Data curation, Formal Analysis, Methodology, Writing original draft. MGPB: Conceptualization, Data curation, Formal Analysis, Methodology, Writing - original draft. WSBM: Conceptualization, Data curation, Formal Analysis, Methodology, Writing - original draft. PRF: Data curation, Formal Analysis, Methodology, Writing - original draft. KVBCS: Conceptualization, Data curation, Formal Analysis, Methodology, Writing - review \& editing. LVA: Conceptualization, Data curation, Formal Analysis, Methodology, Writing - review \& editing. RRJT: Conceptualization, Data curation, Formal Analysis, Methodology, Writing - review \& editing. DBD: Conceptualization, Data curation, Formal Analysis, Methodology, Project administration, Writing review \& editing. 


\section{REFERENCES}

1. Khan MAB, Hashim MJ, King JK, Govender RD, Mustafa H, Kaabi J Al. Epidemiology of type 2 diabetes - global burden of disease and forecasted trends. J Epidemiol Glob Health. 2020;10(1):10711. https://doi.org/10.2991/JEGH.K.191028.001

2. Laiteerapong N, Ham SA, Gao Y, Moffet HH, Liu JY, Huang $E S$, et al. The legacy effect in type 2 diabetes: impact of early glycemic control on future complications (The Diabetes \& Aging Study). Diabetes Care. 2019;42(3):416-26. https://doi. org/10.2337/dc17-1144

3. Bassi D, Arakelian VM, Mendes RG, Caruso FCR, Bonjorno Júnior JC, Zangrando KTL, et al. Poor glycemic control impacts linear and non-linear dynamics of heart rate in DM type 2. Rev Bras Med Esporte. 2015;21(4):313-7. https://doi. org/10.1590/1517-869220152104150003

4. Vaag AA. Glycemic control and prevention of microvascular and macrovascular disease in the Steno 2 study. Endocr Pract. 2006;12(Suppl 1):89-92. https://doi.org/10.4158/ EP.12.S1.89

5. Ghisi GLM, Chaves GSS, Loures JB, Bonfim GM, Britto R. Validation of the Brazilian-Portuguese Version of a short questionnaire to assess knowledge in cardiovascular disease patients (CADE-Q SV). Arq Bras Cardiol. 2018;111(6):841-9. https://doi.org/10.5935/abc.20180169

6. Sousa MR, Mclntyre T, Martins T, Silva E. Questionário dos conhecimentos da diabetes (QCD): propriedades psicométricas. Rev Port Saude Publica. 2015;33(1):33-41. https://doi. org/10.1016/j.rpsp.2014.07.002

7. Matta SR, Luiza VL, Azeredo TB. Adaptação brasileira de questionário para avaliar adesão terapêutica em hipertensão arterial. Rev Saude Publ. 2013;47(2):292-300. https://doi. org/10.1590/S0034-8910.2013047003463

8. Torres HC, Virginia AH, Schall VT. Validação dos questionários de conhecimento (DKN-A) e atitude (ATT-19) de Diabetes Mellitus. Rev Saude Publica. 2005;39(6):906-11. https://doi. org/10.1590/s0034-89102005000600006

9. Curcio R, Alexandre NMC, Torres HC, Lima MHM. Tradução e adaptação do "Diabetes Distress Scale" - DDS na cultura brasileira*. Acta Paul Enferm. 2012;25(5): 762-7. https://doi. org/10.1590/S0103-21002012005000025

10. Canadian Pharmacists Association. CANRISK: the Canadian Diabetes Risk Questionnaire - user guide for pharmacists [internet]. Ottawa: Canadian Pharmacists Association;
2017. [cited on Nov 23, 2020]. Available from: https://www. pharmacists.ca/practice-development-resources/diabetes/ canrisk-the-canadian-diabetes-risk-questionnaire/

11. Conceição ALO, Corrêa NC, Ferreira PR, Rêgo AS, Silva FB, Carvalho STRF, et al. Translation, cross-cultural adaptation and validation of the Finnish Diabetes Risk Score (FINDRISC) for use in Brazilian Portuguese: questionnaire validity study. Sao Paulo Med J. 2020;138(3):244-52. https://doi.org/10.1590/15163180.2019.0524.05032020

12. Guo J, Shi Z, Chen JL, Dixon JK, Wiley J, Parry M. Translation and validation of the Canadian diabetes risk assessment questionnaire in China. Public Health Nurs. 2018;35(1):18-28. https://doi.org/10.1111/phn.12380

13. Beaton DE, Bombardier C, Guillemin F, Ferraz MB. Guidelines for the process of cross-cultural adaptation of self-report measures. Spine (Phila Pa 1976). 2000;25(24):3186-91. https:// doi.org/10.1097/00007632-200012150-00014

14. Prinsen CAC, Mokkink LB, Bouter LM, Alonso J, Patrick DL, Vet $\mathrm{HCW}$, et al. COSMIN guideline for systematic reviews of patientreported outcome measures. Qual Life Res. 2018;27(5):114757. https://doi.org/10.1007/s11136-018-1798-3

15. Cruz PA. Adaptação transcultural do questionário de risco para diabetes mellitus "Take the test. Know your score." [dissertação]. São Paulo: Faculdade de Saúde Pública, Universidade de São Paulo, 2010. https://doi.org/10.11606/D.6.2010.tde-13102010144009

16. Sim J, Wright CC. The kappa statistic in reliability studies: use, interpretation, and sample size requirements. Phys Ther. 2005;85(3):257-68. https://doi.org/10.1093/ptj/85.3.257

17. Fleiss JL. The design and analysis of clinical experiments. New Jersey: John Wiley \& Sons, Inc; 1999. https://doi. org/10.1002/9781118032923

18. Ostelo RW, Vet HC, Knol DL, Brandt PA. 24-item Roland-Morris Disability Questionnaire was preferred out of six functional status questionnaires for post-lumbar disc surgery. J Clin Epidemiol. 2004;57(3):268-76. https://doi.org/10.1016/j. jclinepi.2003.09.005

19. Alghwiri A, Alghadir A, Awad H. The Arab Risk (ARABRISK): translation and validation. Biomed Res. 2014 [Mar. 16, 2021];25(2):271-5. Available from: https://www.researchgate. net/publication/263409086_The_Arab_Risk_ARABRISK_ Translation_and_validation 